Pesq. Vet. Bras. 30(9):749-753, setembro 2010

\title{
Ureia como marcador de diluição em amostras de lavado traqueobrônquico de potros com rodococose ${ }^{1}$
}

\author{
Ana Carolina R.C. Porto ${ }^{2 *}$, Regina M.S. Mirandola², Clara S. Mori² \\ e Wilson R. Fernandes ${ }^{2}$
}

\begin{abstract}
Porto A.C.R.C., Mirandola R.M.S., Mori C.S. \& Fernandes W.R. 2010. [Urea as a dilution mark in tracheobronchial wash samples of foals with rodhococosis.] Ureia como marcador de diluição em amostras de lavado traqueobrônquico de potros com rodococose. Pesquisa Veterinária Brasileira 30(9):749-753. Departamento de Clínica Médica, Faculdade de Medicina Veterinária e Zootecnia, Universidade de São Paulo, Av. Prof. Dr. Orlando Marques de Paiva 87, Cidade Universitária, São Paulo, SP 05508 270, Brazil. Emal: carolporto@usp.br

In the study of infection and inflammatory mechanisms of the lower respiratory tract, the unknown dilution of tracheobronchial wash samples is a serious problem for interpretation of the measured concentrations of various substances. The range of dilution in a true clinical situation was investigated with the goal to determine the validity of using urea dosage in tracheobronchial wash to correct the dilution. The study samples consisted of tracheobronchial wash specimens from 7 foals with Rhodococcus equi infection. Total and differential cell counts were made and compared with clinical status and bacterial recuperation of all samples. The dilution factors of the nasal lavage specimens varied between 14.3 and 130 (median 59.7). The use of urea as a dilution mark improves the accuracy of quantifying total cell concentration in washes. These findings suggest that the most common current practice of meansuring substances in tracheobronchial wash, without correction for the dilution, may induce to false conclusions.
\end{abstract}

INDEX TERMS: Rhodococcus equi, foal, tracheobronchial wash, urea, dilution factors.

RESUMO.- No estudo das infecções e dos mecanismos inflamatórios do trato respiratório posterior, a diluição desconhecida de amostras de lavados traqueobrônquicos leva a um grave problema na interpretação das concentrações de várias substâncias. Foi investigada a amplitude da diluição em uma situação clínica verdadeira, com o objetivo de determinar a validez do uso da dosagem da ureia em lavados traqueobrônquicos para correção da diluição. As amostras do estudo consistiram em lavados traqueobrônquicos obtidos de sete potros com infecção por Rhodococcus equi. Foi realizada a contagem celular total e diferencial e comprado com o quadro clínico e a recuperação bacteriana de todas as amostras. Os fatores de diluição dos lavados variaram entre 14,3 e 130 (média 59,7). O uso da ureia como marcador de diluição melhorou a exatidão

\footnotetext{
${ }^{1}$ Recebido em 23 de março de 2010.

Aceito para a publicação em 17 de abril de 2010.

2 Departamento de Clínica Médica, Faculdade de Medicina Veterinária e Zootecnia (FMVZ), Universidade de São Paulo(USP), Av. Prof. Dr. Orlando Marques de Paiva 87, Cidade Universitária, São Paulo, SP 05508270 , Brasil.*Autor para correspondência: carolporto@usp.br
}

na determinação da concentração total de células nos lavados. Estes resultados sugerem que a prática de mensurar substâncias em lavado traqueobrônquico sem correção da diluição possa induzir a falsas conclusões.

TERMOS DE INDEXAÇÃO: Rhodococcus equi, potro, lavado traqueobrônquico, ureia, fatores de diluição.

\section{INTRODUÇÃO}

A enfermidade respiratória mais frequente em potros de um a cinco meses de idade é a broncopneumonia piogranulomatosa causada pela bactéria Rhodococcus equi, estando associada à mortalidade de potros em todo o mundo e a prejuízos devidos principalmente ao insatisfatório desempenho atlético dos animais, quando adultos. Diferentes técnicas vêm sendo utilizadas para o diagnóstico da rodococose; entre elas, os testes sorológicos, que têm eficiência questionada. Durante muito tempo, o diagnóstico definitivo foi realizado pela cultura microbiológica combinada com o exame citológico do lavado traqueobrônquico (LTB), mas, hoje, as técnicas moleculares para a detecção do $R$. equi em lavados brônquicos de potros representam um avanço 
para o diagnóstico laboratorial da doença (Sellon et al. 1997), sendo o teste da reação em cadeia da polimerase (PCR) rápido, sensível e especifico (Monego 2008). Porém, segundo Giguère et al. (2003), para a realização do diagnóstico definitivo dessa enfermidade é necessário relacionar o estado clínico dos animais, os achados citológicos e o isolamento de $R$. equi, tanto pelo cultivo da bactéria como pela técnica de PCR a partir do LTB, já que o animal pode ser apenas um portador do micro-organismo.

O LTB é uma técnica intensamente utilizada na medicina veterinária desde a década de 70 , quando foi adaptada por Mansmann \& Knight (1972) e Beech (1975) com objetivo de obtenção de conteúdo de secreções das vias aéreas posteriores. Apesar de o LTB ser uma técnica simples, que pode ser realizada a campo, com baixo custo (Beech 1991) e segurança para coleta de componentes celulares e moleculares do pulmão, a quantidade de fluído que retorna pode ser variável. Essa variação limita a interpretação da mensuração do soluto e a comparação entre lavados (Dargaville et al. 1999). Portanto, uma substância que marque o nível de diluição do líquido obtido é muito válida (Kirschivink et al. 2001).

Diferentes estudos vêm investigando componentes endógenos e exógenos como marcadores de diluição (Rennard et al. 1986, McGorum et al. 1993, Restrick et al. 1995, Dargaville et al. 1999). Os marcadores endógenos mais comumente utilizados são a ureia e a albumina (Von Wichert et al. 1993, Dargaville et al. 1999, Kirschvink et al. 2001, Mohamed et al 2001, Fahy et al. 2001, Ziglam et al. 2002, Bertagnon et al. 2007). Proteína total, sódio, cloreto e lgA secretória também foram estudadas (Von Wichert et al. 1993, Dargaville et al. 1999). Entre os marcadores endógenos, a ureia tem se mostrado o melhor e sua validação vem sendo largamente investigada (Rennard et al. 1986, Von Wichert et al. 1993).

O uso de marcadores endógenos é baseado na afirmação que suas concentrações são idênticas em diferentes partes do pulmão, uniformes em diferentes pacientes e independentes de doenças respiratórias. No caso da ureia isso é ainda mais verdadeiro, pois devido ao seu baixo peso molecular $(60 \mathrm{Da})$ e pela grande capacidade de difusão em membranas (Moja et al. 1997), a concentração de ureia no pulmão e consequentemente no LTB é idêntica a do plasma (McGorum et al. 1993, Mohamed et al. 2001).

Devido à importância da coleta de LTB para o diagnóstico da rodococose, à escassa literatura sobre o padrão de LTB recuperado de potros afetados e à crescente utilização do fluído recuperado para a avaliação de diversos componentes imunológicos, o objetivo desse estudo foi determinar a variação do volume de fluído recuperado e validar a utilização da ureia como marcador de diluição para amostras de LTB de potros infectados com $R$. equi.

\section{MATERIAL E MÉTODOS}

Animais. Foram utilizados sete potros da raça Puro Sangue Inglês de 35 a 56 dias de vida. Os animais foram alojados com as respectivas mães em piquetes de capim tanzânia. Como critério de inclusão no experimento foi utilizado a presença de $R$. equi na primeira coleta do lavado traqueobrônquico (LTB).

Procedimento experimental. Este trabalho foi aprovado pelo Comitê de Ética em Experimentação Animal, FMVZ-USP, sob Protocolo no.1012/2006 de 23.3.2007. A técnica utilizada para a coleta de LTB foi a preconizada por Mansmann \& Knight (1972) e modificada por Beech (1975). A coleta foi realizada nos dias 35, 42 e 56 de vida dos animais. Com os potros em estação, com a cabeça e o pescoço estendido foi feita tricotomia e anti-sepsia de uma área de $7 \times 7 \mathrm{~cm}$, na região média do pescoço e cranial á bifurcação do músculo estenocefálico. Foi introduzida uma cânula através da pele entre os anéis traqueais, atingindo o lúmen da traqueia. Através dessa cânula foi introduzido um cateter de polietileno ${ }^{3}$ até alcançar a região da carina. Através do cateter foram inseridos $20 \mathrm{ml}$ de solução fisiológica estéril 0,9\%, a qual foi imediatamente aspirada por meio de sucção leve por seringa. Esse procedimento foi repetido duas vezes a fim de se recuperar um volume satisfatório com representatividade de células. O fluído recuperado de todos os lavados foi filtrado a fim de remover o muco e posteriormente centrifugado por $15 \mathrm{~min} / 1500 \mathrm{rpm} / 4^{\circ} \mathrm{C}$. O sobrenadante foi reservado e o "pellet" ressuspendido em $1 \mathrm{ml}$ de solução salina.

Para o isolamento da bactéria foram retirados $100 \mathrm{ml}$ do LTB e adicionados em placas de agar BHI. Após 48 horas de incubação, foi realizada a verificação da presença de colônias de $R$. equi nas placas.

A contagem total das células do LTB foi realizada em câmara hematimétrica de Neubauer modificada. As preparações celulares para as contagens citológicas foram realizadas por meio de centrifugação de $200 \mu \mathrm{L}$ do fluído ressuspendido a 28xg durante seis minutos em citocentrífuga, conforme descrito por Fernandes et al. (2000). As lâminas foram fixadas com álcool metílico pa e coradas pelo método de Rosenfeld (1947). A leitura das lâminas foi realizada em microscopia óptica de imersão em aumento de $800 x$

Amostras de sangue foram adquiridas imediatamente após a coleta de LTB. A coleta foi realizada por via intravenosa pela punção da veia jugular, em tubos "vacutainer" sem anticoagulante. Para a obtenção do soro, o sangue foi centrifugado por $15 \mathrm{~min} / 1500 \mathrm{rpm} / 4^{\circ} \mathrm{C}$ e o soro transferido para tubos novos de microcentrífuga que foram armazenados a $-20^{\circ} \mathrm{C}$, para posterior determinação da concentração de ureia.

As concentrações de ureia das amostras de LTB e de soro foram determinadas por método enzimático utilizando-se kit comercial $^{4}$, o processamento das amostras foi realizado de acordo com as recomendações do fabricante, e a leitura foi realizada em analisador bioquímico automatizado ${ }^{5}$.

Os fatores de diluição obtidos das amostras de LTB nas três coletas foram determinados pela divisão do valor de ureia do soro pelo valor de ureia do LTB coletados do mesmo animal no mesmo momento, conforme descrito por Fernandes (2001):

$\mathrm{FD}=\mathrm{US} / \mathrm{ULTB}$

Sendo: FD = fator de diluição;

US = ureia do soro;

ULTB = ureia do LTB.

\footnotetext{
3 Cateter Central BD Intracath $₫$, BD do Brasil, Rua Alexandre Dumas 1976, Chácara Santo Antonio, São Paulo, SP.

${ }^{4}$ Urea FS $\AA$, Diasys, Alte Strobe 9, Holzheim, RP, Alemanha.

${ }^{5}$ Lyasis $\AA$, AMS, Via E. Bersanti 17, RO, Itália.
} 
Foi realizado acompanhamento clínico diário dos animais através do monitoramento de alterações nas frequências cardíaca e respiratória, temperatura retal e auscultação pulmonar.

\section{RESULTADOS E DISCUSSÃO}

Apesar de ter sido injetado o mesmo volume de salina em todas as coletas, houve uma variação muito grande de volume recuperado, tanto nas diferentes coletas do mesmo potro, quanto entre os animais (Quadro 1). O menor volume recuperado foi $2,5 \mathrm{ml}$ e o maior foi $27 \mathrm{ml}$ e surpreendentemente foram do mesmo animal. Apenas em dois animais, os volumes recuperados mantiveram-se uniformes, no Potro 1 os volumes foram $12 \mathrm{ml}, 13 \mathrm{ml} \mathrm{e} 12 \mathrm{ml}$ e no Potro 5 os volumes foram $8,5 \mathrm{ml}, 7,5 \mathrm{ml}$ e $7,5 \mathrm{ml}$. Considerando que o maior volume recuperado não representa $50 \%$ do

Quadro 1. Volumes recuperados nas três coletas de lavado traqueobrônquico $(\mathrm{ml})$

\begin{tabular}{cccc}
\hline Potros & Coleta 1 & Coleta 2 & Coleta 3 \\
\hline 1 & 12 & 13 & 12 \\
2 & 11,5 & 4,5 & 10 \\
3 & 28 & 2,5 & 9,5 \\
4 & 25 & 15 & 13,5 \\
5 & 8,5 & 7,5 & 7,5 \\
6 & 10 & 8 & 15 \\
7 & 19 & 7 & 4
\end{tabular}

volume infundido, torna-se difícil a mensuração real de substâncias nesses LTB. Deve-se acreditar também que por serem animais doentes, a possibilidade de existência de secreção pulmonar é grande, o que modifica a diluição do material recuperado. Nos lavados broncoalveolares, aproximadamente $40-60 \%$ do volume infundido é recuperado, porém volumes menores podem ser obtidos, quando ocorrem obstruções, edemas ou broncoespasmos durante a sucção (Hodgson \& Viel 2002). Não foram encontrados dados na literatura sobre volume recuperado de LTB.

A grande dificuldade encontrada na investigação de componentes de fluídos pulmonares é a variação quanto ao volume e composição do fluído recuperado. Essa variação implica em limitação na interpretação das mensurações de soluto, por isso é necessária a utilização de um marcador que indique o grau de diluição do fluído recuperado (Reynolds 1987, Kirschvink et al. 2001).

Uma variedade de substancias tem sido utilizadas como marcadores endógenos de lavados pulmonares (Lotze et al. 1990, Watts et al. 1992, Contreras et al. 1996, ljsselstijn et al. 1998), porém seu uso vem sendo questionado em pacientes com doença pulmonar, já que diversos pesquisadores têm relatado concentrações aumentadas de proteína (Contreras et al. 1996, Le Vine et al. 1996) e albumina, (Watts et al. 1992, Watts \& Bruce 1995) em lavados coletados por diferentes métodos em pacientes com doença pulmonar quando comparados a pacientes controles, sugerindo que é incorreto assumir que a concentração desses componentes é constante no pulmão afetado. Dargaville et al. (1999), estudando crianças com doença pulmo- nar demonstraram que a injúria pulmonar severa não promove um influxo adicional de ureia no pulmão, sugerindo ser a ureia um marcador seguro.

Nas amostras coletadas no primeiro LTB o valor médio do fator de diluição foi 73,9 (variando de 51,5 a 130), no segundo LTB foi de 50,2 (variando de 23,2 a 95) e no terceiro LTB foi de 55,2 (variando de 14,3 a 125). No primeiro lavado todas as amostras estão diluídas mais do que 50 vezes, sendo que $28,5 \%$ estão diluídas mais do que 100 vezes (Fig.1A), já na segunda coleta $42,8 \%$ das amostras estão diluídas mais do que 50 vezes e nenhuma mais do que 100 vezes (Fig.1B) e na terceira coleta $57,1 \%$ estão diluídas mais do que 50 vezes e $14,2 \%$ mais do que 100 vezes (Fig.1C). Não foram encontrados outros estudos semelhantes em equinos para comparação, porém comparando-se com estudo realizado em crianças por Heikkinen et al. (1999), a média do fator de diluição encontrado em nosso estudo foi muito superior $(59,7$ contra 12,7$)$, provavelmente porque em humanos, principalmente crianças, o volume infundido é menor comparado ao utilizado neste experimento.

Segundo Sweeney et al. (1997), o volume de fluído infundido pode ter um impacto na contagem total e diferencial das células recuperadas e, quanto maior o volume infundido menor a concentração de células recuperadas. Em nosso estudo observamos uma variação muito grande na concentração celular, a despeito da utilização de volumes idên-
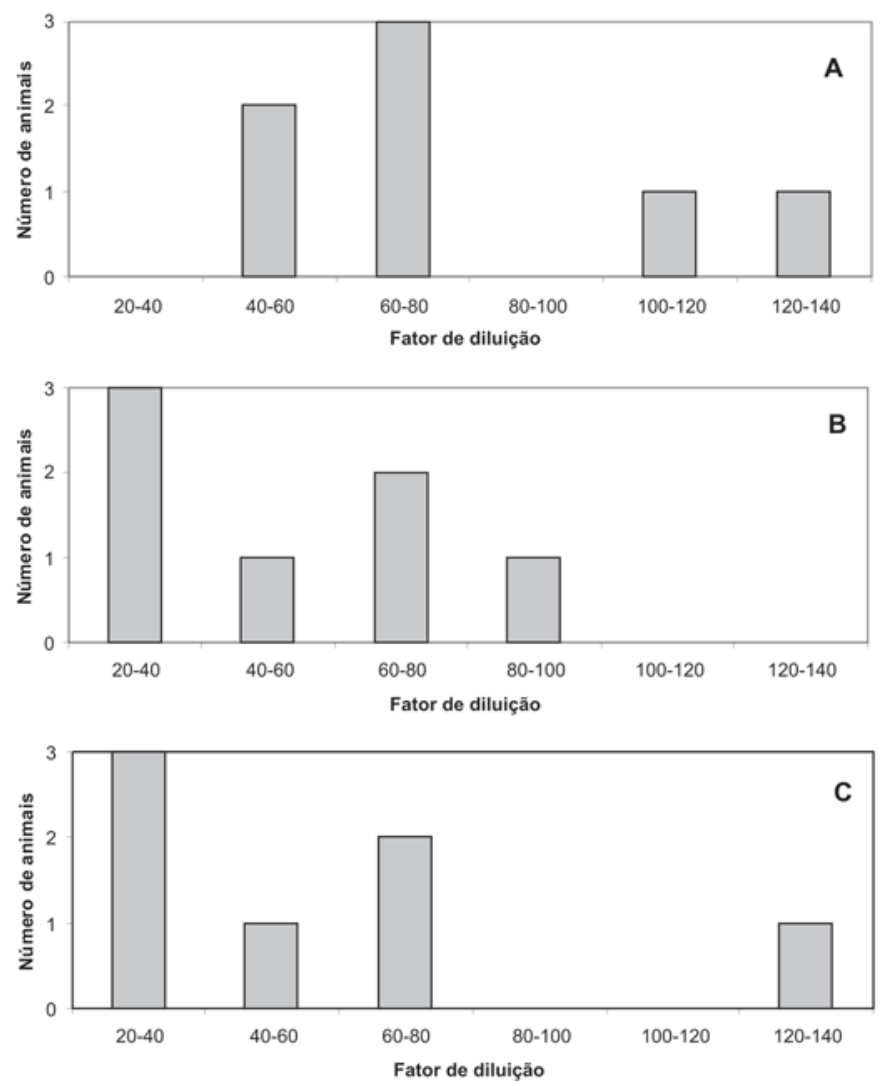

Fig.1. Fator de diluição em amostras de LTB obtidas dos potros na primeiro $(A)$, segunda $(B)$ e terceira $(C)$ coletas. 
ticos nas diferentes coletas. A concentração total de células nas 3 coletas dos 7 potros, depois de corrigida pelo fator de diluição, foi muito superior a concentração inicial (Quadro 2). O valor mínimo conseguido nas amostras iniciais foi 80 células e o máximo foi 12.000 células, já para amostras corrigidas a menor concentração foi 2.680 células e a concentração máxima foi 171.600 células. Após a correção pelo fator proposto, amostra que parecia estar mais concentrada na mensuração inicial em relação à outra amostra, passou a ser menos concentrada (coletas 1 e 2 do Potro 1; Quadro 2). Tal resultado concorda com a afirmação de Beech (1991), de ser a contagem celular total e diferencial de amostras do LTB não confiável devido a variações de volume infundido e recuperado (diluição da amostra). Além disso, os valores iniciais podem levar a uma interpretação errônea sobre o estado de saúde dos animais, já que muitos dos valores obtidos estão dentro da faixa relatada por McGorum et al. (1994), como contagens normais de equinos saudáveis, que variam de 120 a 640 células $\backslash \mu \mathrm{l}$. Os primeiros cinco animais mostraram uma diminuição progressiva na concentração celular, achado que concorda com a melhora significativa do quadro clínico e com a diminuição da recuperação da

Quadro 2. Concentração total de células nucleadas nos lavados traqueobrônquicos $(\mathrm{ml})$ antes e depois da correção pelo fator de diluição

\begin{tabular}{ccccccc}
\hline & \multicolumn{2}{c}{ Coleta 1 } & \multicolumn{2}{c}{ Coleta 2 } & \multicolumn{2}{c}{ Coleta 3 } \\
\cline { 2 - 7 } Potros & Inicial & Corrigida & Inicial & Corrigida & Inicial & Corrigida \\
\hline 1 & 250 & 15.150 & 246 & 19.292 & 275 & 18.645 \\
2 & 95 & 12.434 & 80 & 9.600 & 55 & 2.608 \\
3 & 364 & 22.859 & 240 & 22.800 & 200 & 15.360 \\
4 & 880 & 53.504 & 254 & 15.798 & 140 & 3.598 \\
5 & 300 & 12.000 & 666 & 19.533 & 120 & 6.564 \\
6 & 275 & 27.500 & 1.666 & 48.166 & 3.200 & 72.000 \\
7 & 748 & 38.489 & 6.428 & 149.142 & 9.500 & 190.000
\end{tabular}

Quadro 3. Recuperação bacteriana nos diferentes lavados traqueobrônquicos

\begin{tabular}{cccc}
\hline Potros & Coleta 1 & Coleta 2 & Coleta 3 \\
\hline 1 & $+^{\mathrm{a}}$ & $+^{\mathrm{b}}$ & - \\
2 & + & + & - \\
3 & + & + & - \\
4 & + & + & - \\
5 & + & + & - \\
6 & + & + & + \\
7 & + & + & +
\end{tabular}

a Presença de bactéria; $b$ ausência de bactéria. bactéria no fluído (Quadro 3). Já os dois últimos animais mostraram um aumento progressivo nas concentrações celulares, fato que também concorda com o quadro clínico de piora desses animais, sendo que o Potro 7 morreu cinco dias após a última coleta.

$\mathrm{Na}$ avaliação citológica observou-se na primeira coleta de todos os animais um predomínio de neutrófilos (Quadro 4), o que está de acordo com a observação feita por Hodgson \& Viel (2002) que uma alta concentração de neutrófilos está tradicionalmente associada a uma infecção bacteriana. Já na segunda e na terceira coleta observou-se uma diminuição da concentração de neutrófilos com conseqüente aumento da concentração de macrófagos e linfócitos nos primeiros cinco animais. Observou-se em alguns animais picos de aumento da concentração de linfócitos associados a não mais recuperação da bactéria (Quadro 3). Provavelmente esse aumento de linfócitos contribuiu para promover o "clearence" de Rhodococcus equi do pulmão, já que segundo Hines et al.(2001) o "clearance" de R. equi em animais adultos está associado entre outros fatores com um significante aumento de linfócitos CD4+ e CD8+ no fluido do lavado traqueobrônquico. Já nos Potros 6 e 7 as porcentagens de neutrófilos continuaram predominantes, associada a uma constante recuperação bacteriana. Os resultados obtidos pela avaliação citológica estão de acordo com os dados das concentrações celulares, com os achados clínicos e com a recuperação bacteriana.

Para um correto diagnóstico da rodococose é necessário associar os sinais clínicos com os resultados de isolamento e citologia de lavados obtidos dos animais suspeitos (Giguère et al. 2003). Nesse estudo pudemos observar que existe uma relação muito grande entre a concentração celular, o tipo celular, a recuperação bacteriana e a resolução do quadro clínico. Deve-se apenas salientar que sem a realização da correção da diluição, a interpretação correta fica prejudicada, já que muitas das concentrações obtidas de animais doentes estão dentro da faixa de normalidade encontrada em animais sadios. Tal resultado demonstra que a utilização de um marcador de diluição é indispensável para o estudo de substâncias nos LTB.

\section{CONCLUSÕES}

Os resultados encontrados nesse estudo demonstram que o volume recuperado em diferentes LTBs e consequente fator de diluição variam muito em potros

Quadro 4. Contagem celular diferencial (\%) nos diferentes lavados traqueobrônquicos

\begin{tabular}{|c|c|c|c|c|c|c|c|c|c|}
\hline \multirow[b]{2}{*}{ Potros } & \multicolumn{3}{|c|}{ Coleta 1} & \multicolumn{3}{|c|}{ Coleta 2} & \multicolumn{3}{|c|}{ Coleta 3} \\
\hline & Macrófagos & Neutrófilos & Linfócitos & Macrófagos & Neutrófilos & Linfócitos & Macrófagos & Neutrófilos & Linfócitos \\
\hline 1 & 3 & 92 & 5 & 8 & 92 & 5 & 33 & 63 & 4 \\
\hline 2 & 14 & 64 & 22 & 48 & 44 & 8 & 21 & 68 & 11 \\
\hline 3 & 4 & 92 & 4 & 6 & 40 & 54 & 26 & 40 & 34 \\
\hline 4 & 6 & 90 & 4 & 36 & 57 & 7 & 27 & 63 & 10 \\
\hline 5 & 11 & 83 & 6 & 19 & 70 & 11 & 55 & 14 & 31 \\
\hline 6 & 40 & 48 & 12 & 1 & 98 & 1 & 2 & 96 & 2 \\
\hline 7 & 13 & 82 & 5 & 4 & 95 & 1 & 3 & 94 & 3 \\
\hline
\end{tabular}


com rodococose, uma situação clinica real e presente em nosso meio.

A acurácia da quantificação de substâncias no LTB se torna dependente do conhecimento da diluição da amostra recuperada.

O uso da ureia como marcador de diluição melhorou a exatidão na determinação da concentração total de células nos lavados traqueobrônquicos obtidos de potros com rodococose.

Agradecimentos.- À Fundação de Amparo à Pesquisa do Estado de São Paulo (FAPESP).

\section{REFERÊNCIAS}

Beech J. 1975. Cytology of traqueobronquial aspirates in horses. Vet. Pathol. 24(12):157-164.

Beech J. 1991. Traqueobronquial aspirates, p.90-102 In: Beech J. (Ed.), Equine Respiratory Disorders. Lea and Febiger, Philadelphia.

Bertagnon H.G., Silva P.E.G., Wachholz L., Leal M.L.R., Fernandes W.R. \& Benesi F.J. 2007. Imunoglobulinas no trato respiratório de bezerros sadios durante o primeiro mês de vida. Pesq.Vet. Bras. 27(12):487-490.

Contreras M., Hariharan N., Lewandoski J.R., Ciesielski W., Koscik R. \& Zimmerman J.J. 1996. Bronchoalveolar oxyradical inflammatory elements herald bronchopulmonary dysplasia. Crit. Care Med. 24(1):29-37.

Dargaville P.A., South M., Vervaart P. \& McDougall P. 1999. Validity of markers of diluition in samall volume lung lavage. Am. J. Respir. Crit. Care Med. 160(3):778-784.

Fahy R.J., Diaz P.T., Hart J. \& Wewers M.D. 2001. Bal and serum IgG levels in healthy asymptomatic HIV-infected patients. Chest 119(1):196-203.

Fernandes W.R., Mori E. \& Sanches A. 2000. Avaliação citológica de lavados traqueobrônquico e broncoalveolar em cavalos clinicamente sadios pelo método de coloração de Rosenfeld. Arq. Bras. Med. Vet. Zootec. 52(6):604-609.

Fernandes W.R. 2001. Estudo clínico e da dinâmica de imunoglobulinas séricas e no lavado bronco-alveolar de equinos experimentalmente infectados com herpesvírus equino tipo 1. Tese de Livre Docência, Faculdade de Medicina Veterinária e Zootecnia, USP, São Paulo. 92p.

Giguère S., Hernandez J., Gaskin J, Prescott J.F. \& Takai S., Miller C. 2003. Performance of five serological assays for diagnosis of Rhodococcus equi pneumonia in foals. Clin. Diagn. Lab. Immunol. 10(2):241-245

Heikkinen T., Shenoy M., Goldblum R.M. \& Chonmaitree T. 1999. Quantification of cytokines and inflammatory mediators in samples of nasopharyngeal secretions with unknown dilution. Pediatr. Res. 45(2):230-234.

Hines T.M., Paasch M.K., Alperin C.D., Palmer H.G., Westhoff C.N. \& Hines A.S. 2001. Immunity to Rhodococcus equi: antigen-specific recall responses in the lungs of adult horses. Vet. Immunol. Immunopathol.79:101-113.

Hodgson J. \& Viel L. 2002. Sampling, microbiology and cytology of the respiratory tract. In:Lekeux P. Equine Respiratory Diseases. Disponível em www.ivis.org/special_books/Lekeux/viel/chapter_frm.asp. Acesso em 14 jul. 2009.

ljsselstijn H.L., Zimmermann J.I., Bunt J.E.H., De Jongste J.C. \& Tibboel D. 1998. Prospective evaluation of surfactant composition in bronchoalveolar lavage fluid of infants with congenital diaphragmatic hernia and of age-matched controls. Crit. Care Med. 26(3):573-580.
Kirschvink N., Fiévez L., Dogné S., Bureau F., Art T. \& Lekeux P. 2001. Comparison of inulin with urea as dilutional markersof bronchoalveolar lavage in healthy and heavy-affected horses. Vet. Res. 32(2):145-154.

LeVine A.M., Lotze A., Stanley S., Stroud C., O'Donnell R., Whitsett J. \& Pollack. M.M. 1996. Surfactant content in children with inflammatory lung disease. Crit. Care Med. 24(6):1062-1067.

Lotze A., Whitsett J.A., Kammerman L.A., Ritter M., Taylor G.A. \& Short B.L. 1990. Surfactant protein A concentrations in tracheal aspirate fluid from infants requiring extracorporeal membrane oxygenation. J. Pediatr. 116(3):435-440.

Mansmann R. \& Knight H. D. 1972. Transtracheal aspiration in the horses. J. Am. Vet. Med. Assoc. 160(11):1527-1529.

McGorum B.C., Dixon P.M., Halliwell R.E.W. \& Irnving P. 1993. Evaluation of urea and albumen as endogenous marker of dilution of equine bronchoalveolar lavage fluid. Res. Vet. Sci. 55(1):52-56.

McGorum B.C., Dixon P.M., Halliwell R.E.W. \& Irnving P. 1994. The analysis andinterpretetaion of equine bronchoalveolar lavage fluid (BALF) cytology. Equine Vet. Educ. 6(4):203-209.

Mohamed K.H., Mobasher A.A.M.T., Yousef A.R. I., Salah A., El-Naggar I.Z., Ghoneim A. H.A. \& Light R.W. 2001. BAL Neopterin: A novel marker for cell-mediated immunity in patients with pulmonary tuberculosis and lung cancer. Chest 119(3):776-780.

Moja P.H., Jalil A., Quesnel A., Perol M., Cotte L., Livrozet J.M., Boibieux A., Chamson A., Vergnon J.M., Lucht F., Tran R., Pozzetto B. \& Genin C. 1997. Humoral immune response within the lung in HIV-1 infection. Clin. Exp. Immunol. 110(3):341-348.

Monego F. 2008. Caracterização molecular de Rhodococcus equi de potros pela PCR multiplex dos genes da família vap. Dissertação de Mestrado em Medicina Veterinária Preventiva, UFSM, Santa Maria. 49p.

Reynolds H.Y. 1987. Bronchoalveolar lavage. Am. Rev. Respir. Dis. 135(1):250-263.

Rennard S.I., Basset G., Lecossier D., O'Donnell K.M., Pinkston, P., Martin P.G. \& Crystal

R.G. 1986. Estimation of volume of epithelial lining fluid recovered by lavage using urea as a marker of dilution. J. Appl. Physiol. 60(2):532538.

Restrick L., Sampson A.P., Piper P.J. \& Costello J.F. 1995. Inulin as a marker of dilution of

bronchoalveolar lavage in asthmatic and normal subjects. Am. J. Respir. Crit. Care Med. 151(4):1211-1217.

Sellon D.C., Walker K., Suyemoto M. \& Altier C. 1997. Nucleic acid amplification for rapid detection of Rhodococcus equi in equine blood and tracheal wash fluids. Am. J. Vet. Res. 58(11):1232-1237.

Sweeney C.R., Rossier Y., Ziemer E.L. \& Lindborg S. 1997. Effects of lung site and fluid volume on results of bronchoalveolar lavage fluid analysis in horses. Am. J. Vet. Res. 53(8):1376-1379.

Von Wichert P., Joseph K., Muller B. \& Franck W.M. 1993. Bronchoalveolar lavage: Quantitation of intraalveolar fluid? Am. Rev. Respir. Dis. 147(1):148-152.

Ziglam H.M., Baldwin D.R., Daniels I., Andrews J.M. \& Finch R.G. 2002. Rifampicin concentrations in bronchial mucosa, epithelial lining fluid, alveolar macrophages and serum following a single $600 \mathrm{mg}$ oral dose in patients undergoing fibre-optic bronchoscopy. J. Antim. Chemoth. 50(6):1011-1015.

Watts C.L. \& Bruce. M.C. 1995. Comparison of secretory component for immunoglobulin $A$ with albumin as reference proteins in tracheal aspirate from preterm infants. J. Pediatr. 127(1):113-122.

Watts C.L., Fanaroff A.A. \& Bruce M.C. 1992. Elevation of fibronectin levels in lung secretions of infants with respiratory distress syndrome and development of bronchopulmonary dysplasia. J. Pediatr. 120(4):614-620. 